\section{LIGHTING UP YOUR DENTAL LIFE}

A-dec looks forward to welcoming you to stand E03 at Dental Showcase where you can experience their new, award-winning LED dental light. Optically engineered specifically for dentists and the dental operatory, join the A-dec team to learn more about how the LED light ensures ample illumination, clarity and depth during treatment, whilst reducing eye strain and optimising ergonomics.

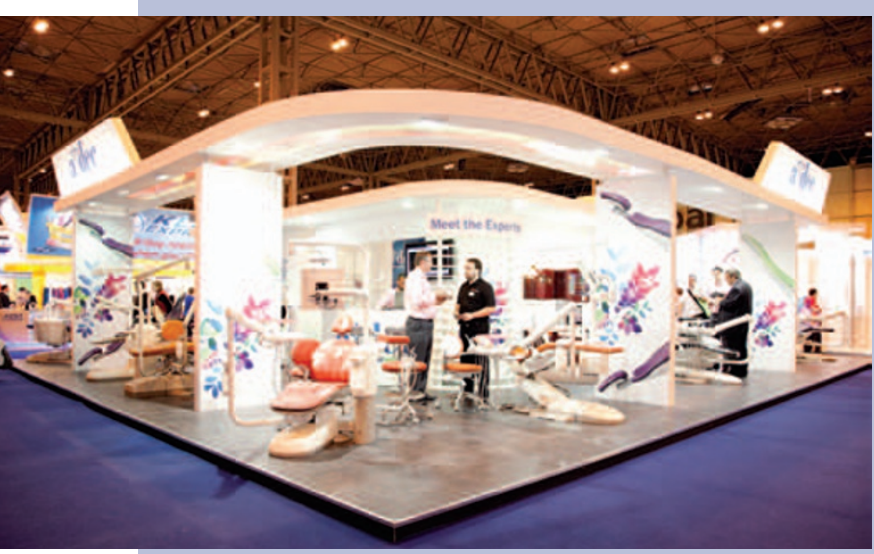

In addition, A-dec will have the full spectrum of dental chairs on display, with integrated options and cabinetry solutions from the current range. See how the A-dec collection of equipment could help you increase productivity, reduce clutter or simply create a relaxed, efficient environment for the benefit of dental team and patient.

A-dec's popular 'Meet the experts' area will also be returning this year, offering design and equipment advice.

New for 2012, in a 'Tweet from the Seat' promotion you can enter a competition via your Twitter account using \#adecuk for the chance to win an iPad each day of Dental Showcase. www.a-dec.co.uk

\section{WIN A YEAR'S SUPPLY OF TOOTHPASTE}

You could win a year's supply of whitening toothpaste from Beverly Hills Formula at this year's BDTA Dental Showcase!

To be in with a chance of winning, simply download your 'Don't forget your toothpaste ticket' from www.beverlyhills. com/toothpaste-ticket and bring it with you to stand B13 where you will be entered into the prize draw. Beverly Hills Formula will announce one winner for each of the three days of the event.

The Beverly Hills Formula range of whitening toothpastes enables your patients to achieve a 'Hollywood smile' without resorting to harsh acids and abrasives or home bleaching kits.

Stand B13. www.

beverlyhillsformula.com

\section{EDUCATE YOUR PATIENTS ON SENSITIVITY}

The Sensodyne team is committed to raising awareness and understanding of dentine hypersensitivity, to make sure that the one in three adults who may suffer are aware of the factors which might predispose to the condition, and that simple interventions, like the use of a desensitising toothpaste, could help relieve their sensitivity.

Sensodyne Repair \&t Protect toothpaste contains advanced NovaMin technology, and is clinically proven to relieve the pain of dentine hypersensitivity.

Support your conversations with patients with the new Sensodyne patient information pieces, available now for your practice. The new pieces include an A4 tent card for use chairside, and a patient questionnaire with display stand for use at reception. Both materials offer information on dentine hypersensitivity, and how a specialist toothpaste such as Sensodyne Repair \& Protect could help.

You can review condition information and order trial sized packs of selected Sensodyne products at www.gsk-dentalprofessionals.co.uk.

Sensodyne will be on stand M06 at this year's Showcase.

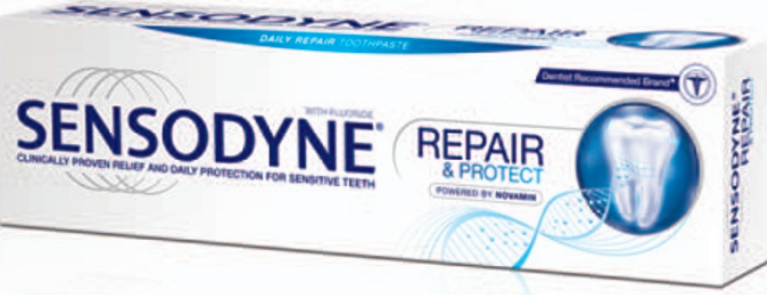

\title{
HOW TO DAZZLE YOUR PATIENTS
}

Open to dentists, dental therapists, nurses and hygienists, membership of the British Dental Bleaching Society offers:

- Training opportunities for the whole dental team

- Support and advice

- Access to the latest bleaching research

- Clarification on legal matters concerning whitening

- Discounts on Dental Directory products

- Free entry to an annual conference.

The Bleaching Society is the only group to provide independent, unbiased advice and training on the latest tooth whitening products and techniques. Eliminating any doubt with bleaching treatment, the BDBS helps members to understand the legalities of whitening, suitability of cases and the best way to perform treatment.

Whitening is the first step to many cosmetic procedures and the most conservative, cost-effective way of improving a patient's smile. Join the Bleaching Society and find out how to dazzle your patients.

www.bdbs.co.uk

\section{EVERYONE'S A WINNER}

dfyt.com (don't forget your toothbrush) is a subscription-based delivery service for toothbrushes and oral hygiene products.

The dfyt.com system is simple. Each practice that registers receives posters and leaflets marked with a practicespecific code. Every patient that subscribes using the code will receive an extra 5\% discount on their order, while the practice will receive $10 \%$ of the order value as revenue.

www.dfyt.com 